\title{
SHS-metallurgy of aluminum oxynitride and its subsequent purification from impurities
}

\author{
V.I. Yukhvid ${ }^{\dagger}$, V.A. Gorshkov, V.N. Borshch, P. A. Miloserdov, N. V. Sachkova, M. I. Alymov \\ †yukh@ism.ac.ru
}

Institute of Structural Macrokinetics and of Materials Science of RAS, 8 Academician Osipyan str., 142432, Chernogolovka, Russia

A promising direction in design of new materials is the development of high-strength transparent ceramics. Examples of fabricating transparent ceramics out of alumomagnesium spinel or leucosapphire are known. However, alumomagnesium ceramics have significantly lower strength than leucosapphire, while the latter is too expensive due to a complexity and low productivity of its technology. One of leading materials for manufacturing high-strength polycrystalline transparent ceramics is aluminum oxynitride composition $\mathrm{Al}_{23} \mathrm{O}_{27} \mathrm{~N}_{5}$ (or $\mathrm{Al}_{5} \mathrm{O}_{6} \mathrm{~N}$ ). Introduction of nitrogen into aluminum oxide results in a formation of an isotropic cubic crystal structure of oxynitride, stabilizes its matrix and gives it a high strength and crack toughness. The present study aims to establish the scientific bases for a new high-performance low power highpurity aluminum oxynitride powder technology $\mathrm{Al}_{23} \mathrm{O}_{27} \mathrm{~N}_{5}$ (Alon), which includes synthesis of ingots by SHS-metallurgy, subsequent disintegration of ingots to obtain powders as well as magnetic and chemical removal of impurities. In experiments in the process reactor SHS-30, it was found that an increase of the weight of a starting mixture from $100 \mathrm{~g}$ to $3 \mathrm{~kg}$ leads to a noticeable change in the desired product composition: nitrogen content increases from 7.7 to $10.8 \% \mathrm{~N}$, and $\mathrm{Al}$ and $\mathrm{O}$ content correspondingly decreases. According to X-ray phase analysis, the main phase in cast oxynitrides is $\mathrm{Al}_{5} \mathrm{O}_{6} \mathrm{~N}$. An appreciable content of $\mathrm{Al}_{7} \mathrm{O}_{3} \mathrm{~N}_{5}$ was also detected. A method for disintegration of cast aluminum oxynitride has been developed, and optimal grinding parameters have been determined that make it possible to obtain powders with a particle size of less than $100 \mu \mathrm{m}$. After grinding, the particles are fragmented. In the integral composition of the particles there are traces of milled steel balls, the material of which is spread over the surface of Alon particles. The magnetic and chemical cleaning practically completely removes impurities (Mo, Al, Fe, AlN) arising due to the incompleteness of chemical transformation, product contamination and milling of steel when grinding.

Keywords: transparent high-strength ceramics, aluminum oxynitride, SHS-metallurgy, chemical transformation, chemical purification.

\section{СВС-металлургия оксинитрида алюминия и последующая его очистка от примесей}

\author{
Юхвид В.И. ${ }^{\dagger}$ Горшков В. А., Борщ В.Н., Милосердов П. А., Сачкова Н. В., Алымов М.И. \\ Институт структурной макрокинетики и проблем материаловедения РАН, ул. Академика Осипьяна 8, 142432, \\ Черноголовка, Россия
}

Перспективным направлением в создании новых материалов является разработка высокопрочной прозрачной керамики. Известны примеры получения прозрачной керамики из алюмо-магниевой шпинели и лейкосапфира. Однако по прочности алюмо-магниевая керамика существенно уступает лейкосапфиру, а стоимость лейкосапфира очень высока из-за сложности и малой производительности технологии. Одним из лидирующих материалов для изготовления высокопрочной поликристаллической прозрачной керамики является оксинитрид алюминия с составом $\mathrm{Al}_{23} \mathrm{O}_{27} \mathrm{~N}_{5}$ (или $\mathrm{Al}_{5} \mathrm{O}_{6} \mathrm{~N}$ ). Введение азота в оксид алюминия приводит к формированию кубической кристаллической изотропной структуры оксинитрида, стабилизирует его матрицу и обеспечивает высокую прочность и трещиностойкость. Настоящее исследование направлено на создание научных основ новой малоэнергоемкой высокопроизводительной технологии получения высокочистого порошка оксинитрида алюминия $\mathrm{Al}_{23} \mathrm{O}_{27} \mathrm{~N}_{5}$ (Алон), включающей в себя синтез слитков методом СВС-металлургии, последующую их дезинтеграцию с получением порошков, а также магнитную и химическую очистку от примесей. В экспериментах в технологическом реакторе СВС-30 установлено, что увеличение массы исходной смеси от 100 г до 3 кг приводит к заметному изменению состава целевого продукта: содержание азота возрастает от 7,7 до $10,8 \% \mathrm{~N}$, содержание O и $\mathrm{Al}$ соответственно уменьшается. По данным рентгенофазового анализа основной фазой в литых оксинитридах является $\mathrm{Al}_{5} \mathrm{O}_{6} \mathrm{~N}$. Выявлено также заметное содержание $\mathrm{Al}_{7} \mathrm{O}_{3} \mathrm{~N}_{5}$. Разработана методика дезинтеграции литого оксинитрида алюминия, определены оптимальные параметры измельчения, позволяющие получать порошки с размером частиц менее 100 мкм. После размола частицы имеют 
осколочную форму. В интегральном составе частиц присутствуют следы намола стальных шаров, материал которых “размазан” по поверхности частиц Алона. Магнитная и химическая очистка практически полностью удаляет примеси (Mo, Al, Fe, AlN), обусловленные неполнотой химического превращения, загрязнением побочным продуктом и намолом стали при измельчении.

Ключевые слова: прозрачная высокопрочная керамика, оксинитрид алюминия, СВС-металлургия, химическое превращение, химическая очистка.

\section{1. Введение}

Перспективным направлением в создании новых материалов является разработка высокопрочной прозрачной керамики. Известны примеры получения прозрачной керамики из алюмо-магниевой шпинели и лейкосапфиpa [1-6]. Однако по прочности алюмо-магниевая керамика существенно уступает лейкосапфиру, а стоимость лейкосапфира очень высока из-за сложности и малой производительности технологии [7].

Одним из лидирующих материалов для изготовления высокопрочной поликристаллической прозрачной керамики является оксинитрид алюминия состава $\mathrm{Al}_{23} \mathrm{O}_{27} \mathrm{~N}_{5}$ (Алон) [8]. Введение азота в оксид алюминия приводит к формированию кубической кристаллической изотропной структуры оксинитрида, стабилизирует его матрицу и обеспечивает высокую прочность и трещиностойкость. Для получения порошков оксинитридов и прозрачной керамики из нее наиболее часто используют методы порошковой металлургии [9-10]. Известны и другие подходы к получению исходных порошков Алона [11-13]. В предшествующих работах авторов была показана возможность получения литых оксинитридов из смесей $\mathrm{CrO}_{3} / \mathrm{Al} / \mathrm{AlN}, \mathrm{Fe}_{2} \mathrm{O}_{3} / \mathrm{Al} / \mathrm{AlN} \mathrm{MoO}_{3} / \mathrm{Al} / \mathrm{AlN}$ методами СВС-металлургии [14-16].

Настоящее исследование направлено на создание научных снов новой малоэнергоемкой высокопроизводительной технологии создания высокочистого порошка Алона, включающей синтез слитков методом СВС-металлургии, последующую их дезинтеграцию и получение порошков, а также магнитную и химическую очистку от примесей.

\section{2. Методика экспериментов}

Методика получения крупньх слитков. Для синтеза литых оксинитридов алюминия применяли порошки оксида молибдена $\left(\mathrm{MoO}_{3}\right)$ с алюминием марки АСД-1 и нитридом алюминия (AlN), полученным в ИСMAН по технологии СВС [17]. Для экспериментов использовали смесь 91\% $\left(\mathrm{MoO}_{3} / 4 \mathrm{Al}\right)+9 \% \mathrm{AlN}$, (здесь и далее $\%$ вес.), состав которой был определен в предыдущих исследованиях [16].

Эксперименты проводили в реакторе СВС-30 [18] при начальном давлении азота 5 МПа. Масса смеси составляла от 100 г до 3000 г.

Смеси перемешивали в барабанном смесителе в течение 30 минут, помещали в графитовые формы, уплотняли на виброустановке. Плотность засыпки составляла 1,6-1,7 г/ см³. Форму со смесью помещали в реактор, вводили азот до нужного давления и герметизировали. Горение инициировали электрической спиралью. Нача- ло и конец горения регистрировали по газовому манометру. После завершения горения реактор охлаждали в течение 0,5 часа, затем газ удаляли и извлекали форму с продуктами горения.

В экспериментах определяли среднюю линейную скорость горения $(u), u=h / t, h-$ высота слоя исходной смеси, $t_{\text {r }}$ - время горения слоя исходной смеси, $t_{\text {г }}$ определяли с помощью регистрации движения стрелки манометра от начального давления до максимального; относительный выход оксинитрида в слиток $\left(\eta_{1}\right)$, $\eta_{1}=\left[\left(m / M_{1}\right)\right] \times 100 \%, m-$ масса оксинитридного продукта, $M_{1}$ - масса исходной смеси; относительную потерю массы смеси при горении $\left(\eta_{2}\right), \eta_{2}=\left[\left(M_{1}-M_{2}\right) / M_{1}\right] \times 100$, $M_{2}$ - суммарная масса оксинитридного и металлического продуктов горения; $\left(M_{1}-M_{2}\right)-$ потеря массы смеси при горении (разброс смеси).

Для проведения исследований по дезинтеграции слитков и очистке от примесей проводили наработки опытных партий по 5-10 кг и аттестацию химического и фазового состава.

Методика дезинтеграции. Полученные слитки Алона измельчали вначале в щековой дробилке (ДЛЩ) и получали гранулы с размером менее 1 мм, затем проводили завершающее измельчение при различных режимах на установке шаровых мельниц. В качестве мелющих тел использовали шары диаметром 3 см, из стали ШХ15.

Методика магнитной и химической очистки. Полученный после измельчения порошок Алона вначале очищали от примесей стали (намол шаров в процессе измельчения) методом магнитной сепарации. Навеску порошка Алона (100 г) после предварительной магнитной очистки кипятили 2 ч в 750 мл $10 \%$-ной $\mathrm{HNO}_{3}$, с последующим отстоем в вытяжном шкафу в течение 8 часов. Остаток высушивали при $70^{\circ} \mathrm{C}$, после чего кипятили в 500 мл 5\%-ного раствора $\mathrm{NaOH} 2$ часа и отстаивали в течение 8 часов. Осадок повторно промывали на тройном бумажном фильтре до нейтральной реакции и высушивали при той же температуре.

Методики исследования слитков и порочков. Химический анализ продуктов СВС-металлургии (оксинитридного и металлического) проводили методами классической аналитической химии. Фазовый состав исследовали методом рентгеновской дифрактометрии на установке Termo Fisher Scientist ARL X'TRA. Для идентификации фазового состава продуктов горения использовали банк данных Powder Diffraction File (PDF2). Для исследования микроструктуры, структурных составляющих оксинитридного и металлического продуктов синтеза применяли автоэмиссионный сканирующий электронный микроскоп сверхвысокого разрешения Zeiss Ultra plus на базе Ultra 55 и рентгеновскую установку Termo Fisher Scientist ARL X’TRA. 


\section{3. Результаты}

Во всех экспериментах продукт горения имел вид двухслойного слитка. Как показали исследования, верхний слой представлял собой оксинитрид алюминия, а нижний - алюминид молибдена. Слои легко отделялись друг от друга. Слитки Алона, полученные в экспериментах, имели следующие весовые и геометрические характеристики: для $M_{1}=100$ г, $m=45$ г, $d=40 \mathrm{mм}, h=10 \mathrm{мм}$; для $M_{1}=3000$ г, $m=1390$ г, $d=100 \mathrm{мм}, h=90 \mathrm{мм}$.

Увеличение массы исходной смеси от 100 г до 3000 г мало изменяет скорость горения, потерю массы и выход Алона в слиток, табл. 1, но приводит к заметному увеличению содержания $\mathrm{N}$ и уменьшению содержания $\mathrm{O}$ и $\mathrm{Al}$ в Алоне, табл. 2, а также устранению примесей $\mathrm{Al}$ и $\mathrm{AlN}$, рис. $1 \mathrm{~b}$. По данным рентгенофазового анализа, рис. 1a-b, основной фазой в литых оксинитридах является $\mathrm{Al}_{5} \mathrm{O}_{6} \mathrm{~N}$. Выявлено также заметное содержание $\mathrm{Al}_{7} \mathrm{O}_{3} \mathrm{~N}_{5}$.

Фото разлома крупного слитка, зоны и результаты анализа представлены на рис. 2 и в табл. 2.

Из таблицы следует, что базовые элементы (Al, O и N) равномерно распределены по объему крупного слитка оксинитрида алюминия. В объеме могут присутствовать отдельные частицы Мо.

Результаты анализа состава структурных составляющих, рис. 3 и табл. 3, показывают: области 1 и 4 по составу близки к фазе $\mathrm{Al}_{7} \mathrm{O}_{3} \mathrm{~N}_{5}$ а области 2 и 3 по составу близки к фазе $\mathrm{Al}_{5} \mathrm{O}_{6} \mathrm{~N}$.

Следует отметить, что на шлифе присутствуют светлые выделения, рис. 3 и табл. 3 (зоны 5 и 6), состав которых позволяет предположить, что это поры, заполненные шлиф-материалами.

Экспериментально установлено, что для получения $100 \%$ выхода порошка Алона с размером частиц менее 100 мкм требуется 20 часов измельчения при соотношении масс гранул и шаров $1: 3$. Распределение по размерам частиц Алона, полученных в этих условиях, приведено на рис. 4. После размола частицы имеют осколочную форму, рис. 5. В интегральном составе частиц присутствуют следы намола стальных шаров, табл. 4. которые, видимо, “размазаны” по поверхности частиц Алона.

Интегральный химический состав частиц Алона до очистки представлен на рис. 6 и в табл. 5, после очистки в табл. 6. Из их анализа следует, что магнитная и химическая очистка практически полностью удаляет примеси (Mo, Al, Fe, AlN), обусловленные неполнотой химического превращения, загрязнения побочным продуктом и намолом при измельчении.

Табл. 1. Влияние масштабного фактора на технологические характеристики и состав Алона $\left(\eta_{1}-\right.$ разброс, $\eta_{2}-$ выход оксида).

Table.1. The effect of the scale factor on the technological characteristics and composition of the Alon ( $\eta_{1}-$ dispersion, $\eta_{2}$ - oxide yield).

\begin{tabular}{|c|c|c|c|c|c|}
\hline \multirow[t]{2}{*}{$\begin{array}{l}\text { Масса } \\
\text { смеси, г } \\
\text { Mass } \\
\text { mixture, g }\end{array}$} & \multicolumn{2}{|c|}{$\begin{array}{c}\text { Технологические } \\
\text { характеристики } \\
\text { Technological } \\
\text { characteristics }\end{array}$} & \multicolumn{3}{|c|}{$\begin{array}{c}\text { Состав Алона, } \\
\% \text { вес. } \\
\text { Alon composition, } \\
\% \text { weight }\end{array}$} \\
\hline & $\eta_{1}$ & $\eta_{2}$ & $\mathrm{Al}$ & $\mathrm{O}$ & $\mathrm{N}$ \\
\hline 100 & 1,5 & 45,0 & 49,1 & 43,2 & 7,7 \\
\hline 3000 & 2,5 & 46 & 50,0 & 39,2 & 10,8 \\
\hline
\end{tabular}
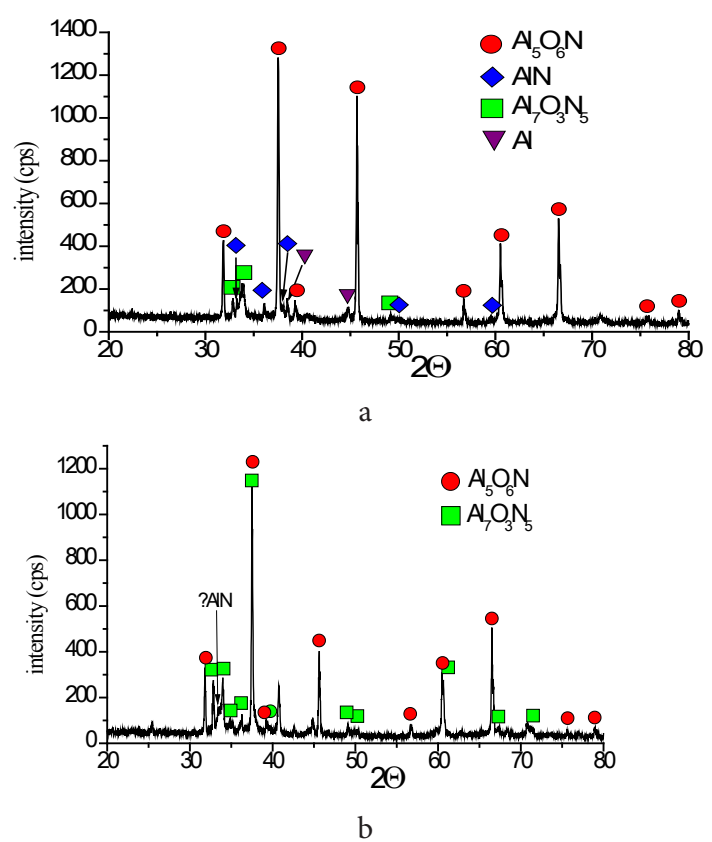

Pис. 1. (color online) Рентгенограмма оксидного слитка: (a) $M_{1}=100 \mathrm{r}$, (b) $M_{1}=3000 \mathrm{r}$.

Fig. 1. (color online) X-ray diffraction pattern of oxide ingot: (a) $M_{1}=100 \mathrm{~g}$, (b) $M_{1}=3000 \mathrm{~g}$.

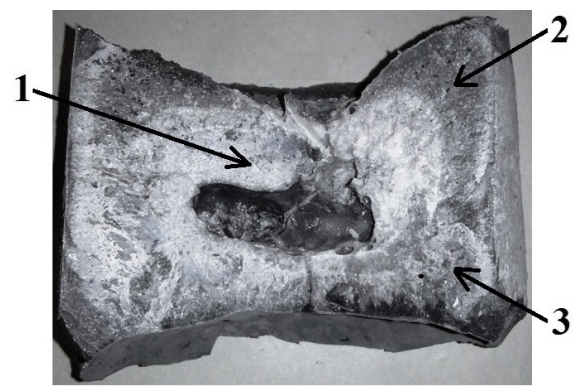

Рис. 2. Разлом оксидного слитка весом 1386,0 г. Исходная смесь: $\mathrm{MoO}_{3} / 4 \mathrm{Al}+9 \% \mathrm{AlN}$.

Fig. 2. The fracture of an oxide ingot weighing $1386.0 \mathrm{~g}$. Initial mixture: $\mathrm{MoO}_{3} / 4 \mathrm{Al}+9 \%$ AlN.

Табл. 2. Интегральный состав оксидного слитка, \% вес.

Table. 2. Integral composition of oxide ingot, $\%$ by weight.

\begin{tabular}{|c|c|c|c|c|}
\hline № & $\mathrm{Al}$ & $\mathrm{O}$ & $\mathrm{N}$ & Mo \\
\hline 1 & 50,0 & 39,2 & 10,8 & - \\
\hline 2 & 50.9 & 41.0 & 8.1 & 0,1 \\
\hline 3 & 48,3 & 41,9 & 9.8 & - \\
\hline
\end{tabular}

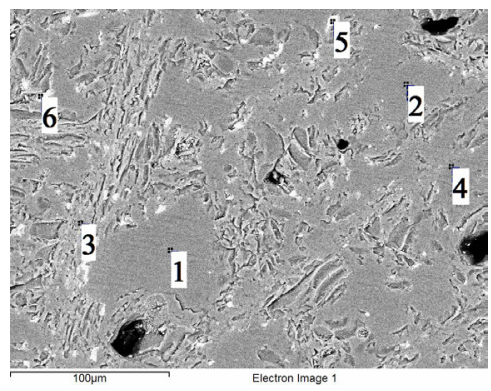

Рис. 3. Распределение элементов в структурных составляющих слитка Алона.

Fig. 3. The distribution of elements in the structural components of the Alon ingot. 


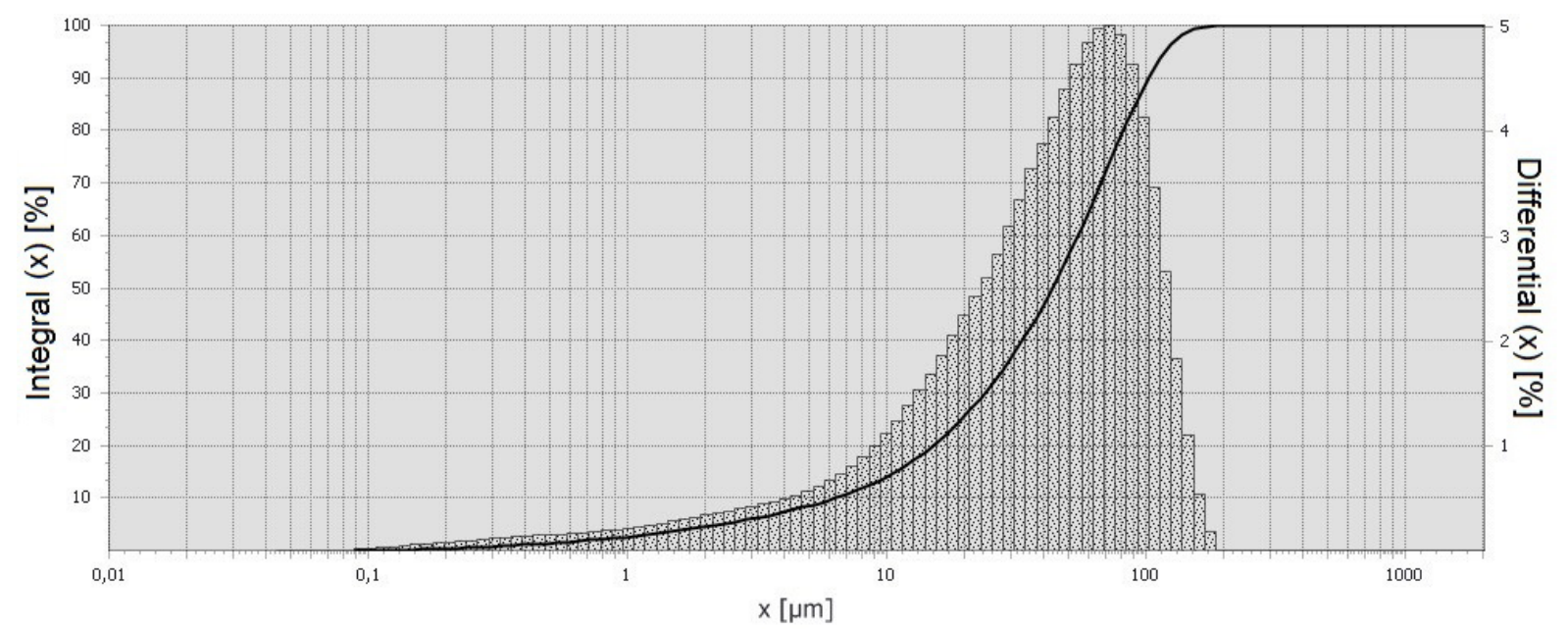

Рис. 4. Распределение частиц порошка Алона по размерам, полученного в оптимальных условиях измельчения.

Fig. 4. Alon powder particle size distribution obtained in the optimum grinding conditions.

Табл. 3. Состав структурных составляющих в слитке Алона. Table.3. The composition of structural components in the Alon ingot.

\begin{tabular}{|c|c|c|c|}
\hline № & $\mathrm{N}$ & $\mathrm{O}$ & $\mathrm{Al}$ \\
\hline 1 & 23.1 & 21.9 & 55 \\
\hline 2 & 7.2 & 45 & 47.8 \\
\hline 3 & 5.8 & 45.4 & 48.8 \\
\hline 4 & 22.6 & 23.3 & 54.1 \\
\hline 5,6 & Поры & Pores \\
\hline
\end{tabular}

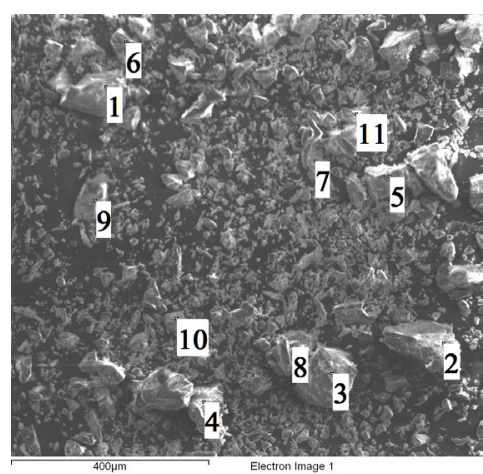

Рис. 5. Частицы Алона после дезинтеграции.

Fig. 5. Alon particles after disintegration.

Табл. 4. Состав частиц Alon после дезинтеграции.

Table 4. Composition of Alon particles after disintegration.

\begin{tabular}{|c|c|c|c|}
\hline \multirow[t]{2}{*}{ № } & \multicolumn{3}{|c|}{$\begin{array}{c}\text { Состав частиц, \% вес } \\
\text { Particle composition, \% weight }\end{array}$} \\
\hline & $\mathrm{Al}$ & $\mathrm{O}$ & $\mathrm{N}$ \\
\hline 1 & 53.2 & 30.1 & 16.7 \\
\hline 2 & 46.1 & 39.8 & 12.2 \\
\hline 3 & 44.0 & 46.3 & 9.7 \\
\hline 4 & 40.6 & 41.1 & 9.8 \\
\hline 5 & 62.1 & 16.9 & 21.0 \\
\hline 6 & 57.6 & 17.0 & 25.4 \\
\hline 7 & 43.0 & 30.8 & 11.0 \\
\hline 8 & 55.6 & 19.7 & 24.1 \\
\hline 9 & 75.5 & 16.6 & 7.9 \\
\hline 10 & 69.9 & 24.5 & 5.6 \\
\hline 11 & 66.1 & 26.4 & 7.5 \\
\hline
\end{tabular}

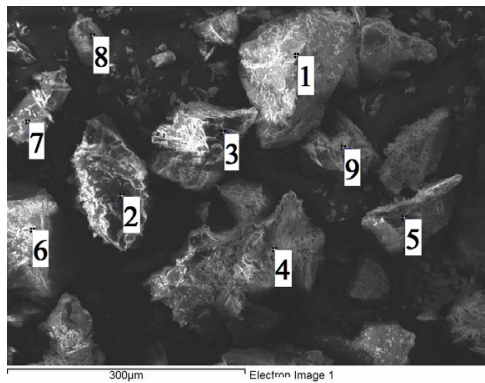

Рис. 6. Частицы порошка литого Алона после измельчения на установке шаровых мельниц.

Fig. 6. The powder particles of the cast Alon after grinding in a ball mill.

табл. 5. Состав частиц Алона после измельчения на установке шаровых мельниц.

Table. 5. Composition of Alon particles after grinding in a ball mill.

\begin{tabular}{|c|c|c|c|c|c|c|}
\hline № & $\mathrm{N}$ & $\mathrm{O}$ & $\mathrm{Al}$ & $\mathrm{Fe}$ & $\mathrm{Ni}$ & $\mathrm{Cr}$ \\
\hline 1 & 5.8 & 38.0 & 54.5 & 1.7 & & \\
\hline 2 & 7.5 & 35.3 & 57.2 & & & \\
\hline 3 & 6.2 & 40.5 & 53.3 & & & \\
\hline 4 & 6.9 & 36.4 & 55.5 & 1.2 & & \\
\hline 5 & 6.5 & 37.7 & 55.3 & 0.5 & & \\
\hline 6 & & 42.4 & 57.6 & & & \\
\hline 7 & 6.0 & 40.4 & 53.0 & 0.6 & & \\
\hline 8 & 6.7 & 34.7 & 50.9 & 3.4 & 2.4 & 1.9 \\
\hline 9 & 6.8 & 35.4 & 56.2 & 1.6 & & \\
\hline
\end{tabular}

табл. 6. Состав частиц Алона после магнитной и химической очистки.

Table. 6. Composition of Alon particles after magnetic and chemical cleaning.

\begin{tabular}{|c|c|c|c|}
\hline & $\mathrm{N}, \%$ & $\mathrm{O}, \%$ & $\mathrm{Al} \%$ \\
\hline $\begin{array}{c}\text { Магнитная очистка } \\
\text { Маgnetic cleaning }\end{array}$ & 12,0 & 40,3 & 47,7 \\
\hline $\begin{array}{c}\text { Химическая очистка } \\
\text { Сhemical cleaning }\end{array}$ & 7,8 & 43,0 & 49,2 \\
\hline
\end{tabular}




\section{4. Обсуждение результатов}

Из анализа экспериментальных результатов следует, что рост массы исходной смеси и, соответственно, массы продукта горения этой смеси приводит к формированию однородного по составу и структуре слитка оксинитрида алюминия и уменьшению примесей в составе целевого продукта (Mo, Al, AlN). Можно указать два основных фактора, которые способствуют этому результату: во-первых, - увеличение интенсивности конвективного движения расплава продуктов химического превращения над фронтом горения, обусловленного градиентом температуры и увеличения диаметра реакционного объема (от 40 мм до 100 мм), [18]; во-вторых, увеличение времени существования расплава продуктов горения, обусловленного снижением скорости охлаждения расплава с ростом реакционного объема.

После измельчения слитков и получения порошка Алона, магнитная сепарация эффективно очищает от магнитных примесей (частиц стали), а последующая обработка кислотой и щелочью приводит к растворению и удалению из Алона примесей исходных компонентов $(\mathrm{Al}, \mathrm{AlN})$ и побочного продукта (Mo).

\section{5. Выводы}

1. Экспериментально изучено влияние масштабного фактора на состав и структуру оксинитридов алюминия. Установлено, что увеличение массы исходной смеси от 100 г до 3000 г приводит к заметному изменению состава Алона: содержание азота возрастает от 7,7 до $10,8 \% \mathrm{~N}$, содержание $\mathrm{O}$ и $\mathrm{Al}$ пропорционально уменьшается.

2. Показано, что основной фазой в литых оксинитридах является Al5O6N. Выявлено также заметное содержание Al7O3N5.

3. Разработана методика дезинтеграции литого Алона, определены оптимальные параметры измельчения, позволяющие получать порошки с размером частиц менее 100 мкм. После размола частицы имеют осколочную форму.

4. Магнитная и химическая очистка практически полностью удаляет примеси (Mo, Al, Fe, AlN), обусловленные неполнотой химического превращения, загрязнения побочным продуктом и намолом стали при измельчении.

Благодарность/Aknowledgements. Для выполнения исследований было использовано оборудование Распределенного Центра Коллективного Пользования ИСМАН. Исследование выполнено при бинансовой поддержке РАН в рамках научного проекта ПРАН № 14.

\section{Литература/References}

1. V.A. Sokol, D.A. Rohlenko, L.I. Konovalova, A. V. Bromberg. Inorg. Mat. 17 (5), 896-901 (1981). (in russian) [В. А. Сокол, Д. А. Рохленко, Л. И. Коновалова, А.В. Бромберг. Неорган. материалы. 17 (5), 896-901 (1981).]
2. Li Ji-Guang, Ikegami T., Lee J.-H., Mory T., Yajima Y. Ceram. Intern. 27 (4), $481-489$ (2001). DOI: 10.1016/S0272-8842 (00) 00107 - 3

3. Shiono T., Shiono K., Miyamoto K., Pezzotti G. J. Amer. Ceram. Soc. 83 (1), 235-237 (2000). DOI: 10.1111/j.1151-2916.2000.tb01180.x

4. Li Ji-Guang, Ikegami T., Lee J.-H., Mory T.J. Am. Ceram. Soc. 83 (11), 2866-2868 (2000). DOI: 10.1111/j.1151-2916.2000.tb01648.x

5. Zinkle S.J. Matzke H., Skuratov V.A. Microstructure of swift heavy ion irradiated $\mathrm{MgAl}_{2} \mathrm{O}_{4}$ spinel // Mater. Res. Soc. Symp. Proc. 540, 299 - 304 (1999)

6. Antonov P.I., Krymov V.M., Nosov Ju.G., Shul'pina I. L. Izvestija AN. Ser. Fiz. 68 (6), $777-783$ (2004). (in russian) [Антонов П.И., Крымов В.М., Носов Ю.Г., Шульпина И.Л. Известия АН. Сер. Физ., 68 (6), $777-783$ (2004)]

7. Krell A, Blank P, Ma HW, Hutzler T, van Bruggen MPB, Apetz R. J Am Ceram Soc. 86 (1), 12 - 18 (2003). DOI: 10.1111/j.1151-2916.2003.tb03270.x

8. McCauleyJ. W., Patel P., Chen M., Gilde G., Strassburger E., Paliwal B., Ramesh K.T., Dandecar D.P. AlON: J. Eur. Ceram. Soc.. 29, 223 - 236 (2009). DOI: 10.1016/j. jeurceramsoc.2008.03.046

9. Yawei L, Nan L. and Runzhang Y. J. Mater. Sci. 32 (4). P. 979-982 (1997,) DOI: 10.1023/A:1018518103842

10. Zientara, D., Bucko, M., Lis, J. J. Eur. Ceram. Soc. 27. (2-3), 775 - 779(2007).DOI:10.1016/j.jeurceramsoc.2006.04.008

11. F. Y. C. Boey, X. L. Song, Z. Y. Gu, A. Tok. J. Mat Proc. Tech. 89 - 90, 478 - 480 (1999). DOI: 10.1016/S0924-0136 (99) 00134-X

12. Gromov A.A., Vereshhagin V.I., Ditc A.A. Ogneupory i tehnicheskaja keramika 12, 19-21 (2004)]. (in russian) [Громов А. А., Верещагин В. И., Дитц А. А.. Огнеупоры и техническая керамика 12, 19-21 (2004)].

13. Galahov A.V., Zelenskij V.A., Kovalenko L.V., Zabelin S.F., Alymov M.I. Uchjonye zapiski ZabGU 3 (50), 22-28 (2013) (in russian) [Галахов А. В., Зеленский В.А., Коваленко Л.В., Забелин С.Ф., Алымов М.И. Учёные записки ЗабГУ 3 (50), 22-28 (2013)]

14. Gorshkov V. A., Tarasov A. G., YukhviD V. I. Russ. J. Phys. Chem. B.4 (2), 304 - 307 (2010). (in russian) [Горшков B.A, Тарасов А. Г., Юхвид В.И. Химическая физика., 29 (4), 51 - 56 (2010)] DOI: 10.1134/S1990793110020168

15. S. L. Silyakov, V. A. Gorshkov, V.I. Yukhvid. Combustion, Explosion, and Shock Waves 48 (4), 428-431 (2012). (in russian) [Силяков С.Л., Горшков В.А., Юхвид В.И. ФГВ, 48 (4), 63-67 (2012)]. DOI: $10.1134 / \mathrm{S} 0010508212040089$

16. П.А. Милосердов, В.И. Юхвид, В.А. Горшков, М.И. Алымов.. Персп.мат., 6, 69 - 76 (2017).

17. V. V. Zakorzhevskii, I.P. Borovinskaya. Inorg. Mat. 51 (6), 566-571 (2015). (in russian) [Закоржевский В.В., Боровинская И. П. Неорг. мат. 51 (6), 628 - 634 (2015)]. DOI: $10.1134 /$ S0020168515060187

18. S.L. Silyakov, V.N. Sanin, V.I. Yukhvid. Combustion, Explosion, and Shock Waves. 47 (5), 523 - 527 (2011). (in russian) [С. Л. Силяков, В.Н. Санин, В. И. Юхвид. ФГВ, 47 (5) 29 - 34 (2011)]. DOI: 10.1134/S0010508211050054 